\title{
Effect of Life Skill Training on Life Style and Health Concern of Adolescents
}

\author{
Dr. Ritu ${ }^{1 *}$
}

\section{ABSTRACT}

Today the need to analyze health behaviour is as imminent as ever, particularly at school. Adolescent students find themselves in a new, challenging and competitive environment; most of them are experiencing independence and responsibility for the first time in their lives. During this time they consequently adopt new health behaviours and there may be a risk that they continue with unhealthy lifestyle choices that were established during their adolescent years, which makes them a risk group not only during these years but for the rest of their lives. Therefore, the purpose of the present study was to investigate the effect of life skill training in adolescent after obtaining the life style and health concern of adolescents and examined associations between lifestyle and health concern. Total sample comprised of 60 students (12 to14 years of age) from Rohtak District of Haryana, who has received life skill training. Life Style Schedule and Adolescent Health Concern Inventory were administered in a group session one by one both before training was given and after the training was over. The results showed that subjects improved significantly in post condition on life style and health concern. This suggests that life skill training has a positive effect on life style and health concern of adolescents. Also, a significant relationship has been obtained between the life style and adolescent health concern. Based on the findings, it is necessary to prioritize implementing of health related life skill programs in order to change and modify the unhealthy life style related factors. Also it is needed to provide special facilities to select healthy living behaviors among adolescents.

Keywords: Life Skill Training, Life Style, Health Concern and Adolescents

Now a days, health promotion is increasingly paid more attention (Adams, Bowden, Humphery, Mc Adams, 2013) and one of the main challenges of countries is providing health care (Ochieng, 2006) according to the health promotion approaches so that people could be made capable to be responsible for their own health and follow healthy life style (Spratt, Shucksmith, Philip,

\footnotetext{
${ }^{1}$ Extension Faculty, Department of Psychology, Government College, Jind, Haryana, India *Responding Author

Received: February 24, 2017; Revision Received: March 23, 2017; Accepted: March 29, 2017

(C) 2017 Ritu; licensee IJIP. This is an Open Access Research distributed under the terms of the Creative Commons Attribution License (www.creativecommons.org/licenses/by/2.0), which permits unrestricted use, distribution, and reproduction in any Medium, provided the original work is properly cited.
} 


\section{Effect of Life Skill Training on Life Style and Health Concern of Adolescents}

Watson, 2006). This practice should be started from childhood and adolescence and keep individuals safe against major health risk during their life (Amir et al, 2008).

The young are the future of society, but they are also very much its present. Adolescents who are healthy and happy are better equipped to contribute to their communities as young citizens despite the major shifts occurring in the world they are about to inherit. Bad habits and poor hygiene, persistent behavioural risks, poor basic sanitation, and new and emerging diseases are contributing to a deadly mix that is changing the classic picture of healthy youth.

Lifestyle behaviours are usually formed during youth (Steptoe et al., 2002). Students find themselves in a new, challenging and competitive environment; most of them are experiencing independence and responsibility for the first time in their lives. During this time they consequently adopt new health behaviours and there may be a risk that they continue with unhealthy lifestyle choices that were established during their adolescent years, which makes them a risk group not only during these years but for the rest of their lives.

There is an interlock relationship between health problems and life style. In other words, life style is one of the most important influential factors on individual's health and illness (Tashiro, 2002). On the basis of statistical data, $53 \%$ of deaths are related to the life style (Baroogh, Nuktehdan, Kazemnejad, Nuruzi, 2003). Healthy life style causes a balance in life in which a person chooses intentional standards options for himself ( $\mathrm{Li}$ et al, 2008). In fact, healthy life style has been considered as a valuable source for decreasing health problems, promoting health, managing stressful events and improving the quality of life (Rafifar, et al, 2005). World Health Organization has predicted that life style is responsible for around $70 \%-80 \%$ of mortality rate in developed and $40 \%-50 \%$ in developing countries (Norman, Kaplan, 2004). Considering the fact that the attitudes and behaviors of students which is said to be formed during young adulthood (Neumark, 2006) are often a determinant of healthy lifestyle habits, and helping adolescents makes healthy lifestyle choices and preventing them from malicious behavior is crucial. Besides, in order to prevent these malicious behaviors, healthy lifestyle should be established in adolescence (Amir et al, 2008).

A substantial number of studies have been generated reporting that adolescent students engage in unhealthy lifestyle behaviours such as substance abuse (Fromme, Corbin, \& Kruse, 2008; Halperin, Smith, Heiligenstein, Brown, \& Fleming, 2010; Vaughan, Corbin, \& Fromme, 2009; White et al., 2006), physical inactivity (Greene et al., 2011; Ulla Diez \& Perez-Fortis, 2010; Von Bothmer \& Fridlund, 2005) and poor diet (Sira \& Pawlak, 2010). In addition, many adolescent students experience stress caused by a number of factors, e.g. failing classes, competition or social pressure, which can result in other health problems such as insufficient sleeping patterns or a decrease in mental wellbeing. 


\section{Effect of Life Skill Training on Life Style and Health Concern of Adolescents}

Only few studies have attempted to link life style with self-rated health among students. One study by Dodd et al.(2010) clustering five lifestyle factors (smoking, physical activity, binge drinking, fruit and vegetable intake and psychological stress) in students in higher education in Great Britain found that nearly half of the sample (46\%) was characterized as having an unhealthy lifestyle. This subgroup consisted of a larger percentage of female as well as a higher percentage of Asian or Asian British and Black or Black British students (Dodd et al., 2010).

Health information and knowledge about diseases and about bodily conditions and functions are evident determinants of health status and outcomes. However, as information (learning to know) is only useful if reinforced by positive attitudes (learning to be) and useful skills (learning to do), the ability to recognize a potential problem must be accompanied by the will and the identification of the means necessary to avoid it.

World Health Organization has advocated the development of life skills in order to promote psychosocial competence. Psychosocial competence is a person's ability to deal effectively with the demands and challenges of everyday life. It is a person's ability to maintain a state of well being, and to demonstrate this in adaptive and positive behaviour while interacting with others, in his/her culture and environment.

Psychological competence has an important role to play in the promotion of health, in terms of physical, mental and social well-being. Enhancement of psychological competence could make an important contribution to well being of individuals, especially, where health problems are related to behaviour, and where the behaviour is related to an inability to deal effectively with stress and pressures in life. In school- based programs for children and adolescents, the teaching of life-skills in a supportive learning environment can do this (WHO, 1994).

Life skills are abilities for adaptive and positive behaviour that enable individuals to deal effectively with the demands and challenges of everyday life. Research has shown that if we have the information and knowledge available to people and create situations where people can experience their learning practically, then this knowledge, values and attitudes will be changed into the potential abilities. This ability helps people to know what to do in any position and how to do it (Soltani 2007).

A research conducted by Bagheri and Bahrami (2011) showed that life skills training to students make significant changes in knowledge, attitudes and self-esteem. Penter (2012) have done a study on teaching life skills in guidance and high schools and the results expressed that life skills training program was used for the prevention of suicide, violence and negative behaviors and academic failure. Gilbert (2011), one of the main goals in life skills, is improving mental health in children and adolescents. Many studies were done about the impact of life skills training program on various aspects of mental health, and the results have shown that training these skills 


\section{Effect of Life Skill Training on Life Style and Health Concern of Adolescents}

increase self-esteem, improve social skills and interpersonal relationships, increase positive social behavior and social adjustment, increase family system satisfaction and adjustment with family, increase problem solving skills.

A large number of articles have been published on health and lifestyle behaviours among students in various countries possibly dominated by the United States and South-East Asia, but there is a dearth of studies which focus on Indian school students and their lifestyle and health behaviours with reference to life skill training. Due to the importance of life skill training in students and the urgency of analyzing health behaviour of adolescent students' the present study is very much relevant and will be of great help in recognizing adolescent's views and perspectives in relation to a particular type of life style and health concern. It also provides opportunity for health authorities and helpful in evaluating adolescents' life style and health concern as well as in planning appropriate preventive approaches in order to develop adolescents' capabilities. On the other hand, schools could provide appropriate atmosphere for teaching healthy life styles to adolescents and as a result will influence the community health. Thus, this study aimed to study the effect of life skill training in adolescent after obtaining the life style and health concern of adolescents and examined associations between lifestyle and health concern.

\section{Hypotheses}

1. There would be significant effect of life skill training on life style of school students.

2. There would be significant effect of life skill training on health concern of adolescents.

3. There would be significant correlation between life style and adolescent health concern.

\section{METHODOLOGY}

A pre and post test design was adopted to assess the effect of the life skill training program. Life Skill Training was conducted collectively in 13 sessions at alternate day, one session per day for 60 minutes. The training program includes theoretical and practical content with providing activities (individual and group).

\section{Sample}

The sample included 60 students in the age group of 12 to 14 years (Mean=13.15; S.D= .78) studying in grade 8 in schools of urban localities from Rohtak City of Haryana.

\section{Tools}

For collecting the required data for both pre - and post test conditions following questionnaires were used:

1. Lifestyle Schedule: A detailed lifestyle schedule which was constructed on the basis of leading health indicators mentioned by the US department of Health and Human Services (HSS) (Healthy People 2010, 2000) was used. The Leading Health Indicators include

(C) The International Journal of Indian Psychology, ISSN 2348-5396 (e)| ISSN: 2349-3429 (p) | 19 


\section{Effect of Life Skill Training on Life Style and Health Concern of Adolescents}

individual behaviours, physical and social environmental factors and other important health system issues that greatly affect the health of individuals and communities. The different lifestyle dimensions that were included in the lifestyle schedule are Physical Activity, Sleep, Nutrition \& Health, Mental/Social Health, Injury \& Violence, Environmental Quality and Health Care \& Immunization.

2. Adolescent Health Concern Inventory: This questionnaire was constructed by Madhu Anand and Anju in 2014. It is a self-administered inventory for adolescents. This inventory has 45 statements belong to 4 domains of Health concern such as Physical Domain, Social Domain, Psychosexual Domain and Moral Domain. The full test reliability was found to be $0.74(\mathrm{p}<.01)$. The Internal Consistency Reliability was found to be $0.87(\mathrm{p}<.01)$. The Test-Retest reliability was .64 $(\mathrm{p}<.01)$.

\section{Procedure}

The present research has been conducted in three phases:

Phase I: The Life Style Schedule and Adolescent Health Concern Inventory were administered on all the 60 students between the age group of 12 and 14 . The instructions for the tests were given to the subjects by the research investigator and the doubts were clarified before they started giving the responses. When there was a difficulty in understanding the statements, they were explained individually.

Phase II: All students were given life skill training program (health-related life skills). The training program consisted of the following activities:

\begin{tabular}{|c|c|}
\hline Session No. & Activity \\
\hline 1. & Introduction and information regarding formation of groups. \\
\hline 2. & Challenge the student's minds with the concept of skills and how to learn skill. \\
\hline 3. & The introduction of life skills as a health promotion program \\
\hline 4. & Learning about healthy food and nutrition. \\
\hline 5. & Learning about healthy drinks \\
\hline 6. & Learning about the importance of physical activities. \\
\hline 7. & Learning about "Eat smart, play hard" \\
\hline 8. & Understanding "Internet and smart phone usage" \\
\hline 9. & Familiarity with mode of relaxation to keep good health. \\
\hline 10. & Knowing about the importance of sound sleep. \\
\hline 11. & $\begin{array}{l}\text { Understanding the role of stress in human life. Familiarity with methods for } \\
\text { dealing with stress. }\end{array}$ \\
\hline 12. & Knowing about the importance and ways of good health and better life style. \\
\hline 13. & $\begin{array}{l}\text { Feedback and Questions: To know that all the students understood and followed } \\
\text { the activities well. }\end{array}$ \\
\hline
\end{tabular}

Phase III: After 10 days of completing 13 sessions of life skill training program, The Life Style Schedule and Adolescent Health Concern Inventory were administered again on all the students, to assess the success of the training program. The obtained data was manually scored and 


\section{Effect of Life Skill Training on Life Style and Health Concern of Adolescents}

statistically analysed by mean, standard deviation and t-test. Correlation between the variables was assessed by means of the Pearson's correlation coefficient.

\section{RESULTS}

The result of the study is presented below

Table 1: Mean, SD and t value of Pre and Post test condition on Life Style

\begin{tabular}{|c|c|c|c|c|c|}
\hline \multirow[t]{2}{*}{ Variables } & \multicolumn{2}{|c|}{ Pre - Test } & \multicolumn{2}{|c|}{ Post - Test } & \multirow[t]{2}{*}{ t-value } \\
\hline & Mean & SD & Mean & SD & \\
\hline Overall Life Style & 41.93 & 5.61 & 49.30 & 3.98 & $8.29 * *$ \\
\hline Physical Activity & 5.25 & 1.59 & 6.30 & 1.56 & $3.66 * *$ \\
\hline Sleep & 3.50 & 0.75 & 3.90 & 0.44 & $3.57 * *$ \\
\hline Tobacco Abuse & 0.00 & 0.00 & 0.00 & 0.00 & 0.00 \\
\hline Substance Abuse & 0.00 & 0.00 & 0.00 & 0.00 & 0.00 \\
\hline Nutrition \& Health & 6.18 & 1.48 & 7.65 & 1.13 & $6.10 * *$ \\
\hline Mental/Social Health & 16.73 & 2.46 & 18.73 & 1.92 & $4.96 * *$ \\
\hline Injury \& Violence & 3.40 & 0.92 & 4.38 & 0.61 & $6.87 * *$ \\
\hline Environmental Quality & 3.28 & 0.85 & 4.02 & 0.70 & $5.17 * *$ \\
\hline Health Care \& Immunization & 3.57 & 1.11 & 4.32 & 0.77 & $4.30 * *$ \\
\hline
\end{tabular}

** Sig. at 0.01 level

The table 1 shows that there was significant difference between pre and post test conditions on life style of school students. There was a significant difference between pre and post condition scores of Overall Life Style $(\mathrm{t}=8.29, \mathrm{p}<.01)$, Physical Activity $(\mathrm{t}=3.66, \mathrm{p}<.01)$, Sleep, $(\mathrm{t}=3.57$, $\mathrm{p}<.01)$, Nutrition \& Health $(\mathrm{t}=6.10, \mathrm{p}<.01)$, Mental/Social Health $(\mathrm{t}=4.96, \mathrm{p}<.01)$, Injury \& Violence $(\mathrm{t}=6.87, \mathrm{p}<.01)$, Environmental Quality $(\mathrm{t}=5.17, \mathrm{p}<.01)$, and Health Care \& Immunization $(\mathrm{t}=4.30, \mathrm{p}<.01)$. However, school students have given no response for tobacco abuse and substance abuse which indicates that probably they are unconcerned about these variables. Thus, first hypothesis which stated significant effect of life skill training on life style of school students is accepted.

Table 2: Mean, SD and t value of Pre and Post condition on Adolescent Health Concern

\begin{tabular}{|c|c|c|c|c|c|}
\hline \multirow[t]{2}{*}{ Variables } & \multicolumn{2}{|c|}{ Pre - Test } & \multicolumn{2}{|c|}{ Post - Test } & \multirow[t]{2}{*}{ t-value } \\
\hline & Mean & SD & Mean & SD & \\
\hline Overall Health Concern & 24.47 & 2.03 & 27.13 & 2.04 & $7.18 * *$ \\
\hline Physical Health Domain & 7.22 & 1.12 & 7.87 & 1.14 & $3.15^{* *}$ \\
\hline Social Health Domain & 4.30 & 0.96 & 4.95 & 0.98 & $3.66 * *$ \\
\hline Psychosexual Health Domain & 5.83 & 1.79 & 6.68 & 1.84 & $2.57 * *$ \\
\hline Moral Health Domain & 7.12 & 1.11 & 7.63 & 1.03 & $2.65 * *$ \\
\hline
\end{tabular}

** Sig. at 0.01 level 


\section{Effect of Life Skill Training on Life Style and Health Concern of Adolescents}

The table 2 shows that there was significant difference between pre and post condition on health concern of adolescents. Significant difference between pre and post condition in Overall Health Concern $(\mathrm{t}=7.18, \mathrm{p}<.01)$, Physical Health Domain $(\mathrm{t}=3.15, \mathrm{p}<.01)$, Social Health Domain $(\mathrm{t}=3.66, \mathrm{p}<.01)$, Psychosexual Health Domain $(\mathrm{t}=2.57, \mathrm{p}<.01)$, and Moral Health Domain $(\mathrm{t}=$ 2.65, $\mathrm{p}<.01$ ) have also been observed. Therefore, second hypothesis which stated significant effect of life skill training on health concern of adolescents is verified.

Table 3: Showing correlation between Life Style and Adolescent Health Concerns

\begin{tabular}{|l|l|l|l|l|l|}
\hline Variables & $\begin{array}{l}\text { Overall } \\
\text { Health } \\
\text { Concern }\end{array}$ & $\begin{array}{l}\text { Physical } \\
\text { Health } \\
\text { Domain }\end{array}$ & $\begin{array}{l}\text { Social } \\
\text { Health } \\
\text { Domain }\end{array}$ & $\begin{array}{l}\text { Psychosexual } \\
\text { Health } \\
\text { Domain }\end{array}$ & $\begin{array}{l}\text { Moral } \\
\text { Health } \\
\text { Domain }\end{array}$ \\
\hline Overall Life Style & $.73^{* *}$ & $.31^{* *}$ & $.34^{* *}$ & $.42^{* *}$ & $.26^{* *}$ \\
\hline Physical Activity & $.51^{* *}$ & $.18^{*}$ & $.22^{* *}$ & $.31^{* *}$ & $.20^{*}$ \\
\hline Sleep & $.34^{* *}$ & .08 & .03 & $.33^{* *}$ & .09 \\
\hline Tobacco Abuse & 00 & 00 & 00 & 00 & 00 \\
\hline Substance Abuse & 00 & 00 & 00 & 00 & 00 \\
\hline Nutrition \& Health & $.58^{* *}$ & $.34^{* *}$ & $.29^{* *}$ & $.29^{* *}$ & .17 \\
\hline Mental/Social Health & $.58^{* *}$ & $.21^{*}$ & $.32^{* *}$ & $.35^{* *}$ & $.18^{*}$ \\
\hline Injury \& Violence & $.47^{* *}$ & $.23^{*}$ & .16 & $.34^{* *}$ & .07 \\
\hline $\begin{array}{l}\text { Environmental } \\
\text { Quality }\end{array}$ & $.41^{* *}$ & .12 & $.24^{* *}$ & $.22^{*}$ & $.19^{*}$ \\
\hline $\begin{array}{l}\text { Health Care \& } \\
\text { Immunization }\end{array}$ & $.33^{* *}$ & $.21^{*}$ & .11 & .09 & $.25^{* *}$ \\
\hline
\end{tabular}

** Sig at 0.01 level; * Sig at 0.05 level

The table 3 shows the correlation coefficient of Life Style and Adolescent Health Concerns. Results revealed that there was a positive correlation between Life Style and Adolescent Health Concerns which indicates that higher the score of life style, the subject's life style would be good and higher the score of health concern, the subjects would be more concerned about health. The correlation coefficient of overall Life Style was found to be positively correlated with Overall Health Concern $(\mathrm{r}=.73, \mathrm{p}<.01)$, Physical Health Domain $(\mathrm{r}=.31, \mathrm{p}<.01)$, Social Health Domain $(\mathrm{r}=.34, \mathrm{p}<.01)$, Psychosexual Health Domain $(\mathrm{r}=.42, \mathrm{p}<.01)$ and Moral Health Domain $(\mathrm{r}=.26$, $\mathrm{p}<.01$ ). The first dimension of Life Style i.e. Physical Activity was found to be positively correlated with Overall Health Concern ( $r=.51, \mathrm{p}<.01$ ), Physical Health Domain $(\mathrm{r}=.18, \mathrm{p}<.05)$, Social Health Domain $(\mathrm{r}=.22, \mathrm{p}<.05)$, Psychosexual Health Domain $(\mathrm{r}=.31, \mathrm{p}<.01)$ and Moral Health Domain $(\mathrm{r}=.20, \mathrm{p}<.05)$. Similarly, Sleep was found to be positively correlated with Overall Health Concern $(r=.34, \mathrm{p}<.01)$ and Psychosexual Health Domain $(r=.33, \mathrm{p}<.01)$. Also, Nutrition \& Health dimension of life style was found to be positively correlated with Overall Health Concern ( $\mathrm{r}=58, \mathrm{p}<.01$ ), Physical Health Domain $(\mathrm{r}=.34, \mathrm{p}<.01)$, Social Health Domain $(\mathrm{r}=.29, \mathrm{p}<.01)$ and Psychosexual Health Domain $(\mathrm{r}=.29, \mathrm{p}<.01)$. The finding reveals that Mental/Social Health was positively correlated with Overall Health Concern $(r=.58, p<.01)$, 


\section{Effect of Life Skill Training on Life Style and Health Concern of Adolescents}

Physical Health Domain $(\mathrm{r}=.21, \mathrm{p}<.05)$, Social Health Domain $(\mathrm{r}=.32, \mathrm{p}<.01)$, Psychosexual Health Domain $(\mathrm{r}=.35, \mathrm{p}<.01)$ and Moral Health Domain $(\mathrm{r}=.18, \mathrm{p}<.05)$. However, Injury \& Violence was found to be positively correlated with Overall Health Concern $(r=.47, \mathrm{p}<.01)$, Physical Health Domain $(\mathrm{r}=.23, \mathrm{p}<.05)$ and Psychosexual Health Domain $(\mathrm{r}=.34, \mathrm{p}<.01)$. It was found that Environmental Quality was positively correlated with Overall Health Concern ( $\mathrm{r}=.41$, $\mathrm{p}<.01)$, Social Health Domain $(\mathrm{r}=.24, \mathrm{p}<.01)$, Psychosexual Health Domain $(\mathrm{r}=.22, \mathrm{p}<.01)$ and Moral Health Domain $(\mathrm{r}=.19, \mathrm{p}<.051)$. The Health Care \& Immunization dimension of life style was found to be positively correlated with Overall Health Concern $(\mathrm{r}=.33, \mathrm{p}<.01)$, Physical Health Domain $(\mathrm{r}=.21, \mathrm{p}<.05)$ and Moral Health Domain $(\mathrm{r}=.25, \mathrm{p}<.01)$. Therefore, third hypothesis which stated significant correlation between life style and adolescent health concern is accepted.

\section{DISCUSSION}

Since education is an organization that can train creative, healthy, thoughtful and efficient human beings and since the base of health programs is prevention, the role of the school as one of the main centers of prevention is important. Therefore, life skills training can definitely help students in direction to life style, health and other life problems. The present study focuses on these life skills as youth survival skills in healthy conditions and, using the framework of WHO's definition of three aspects in health: physical, psychological, and social aspects, aims to understand the skills that are useful in enhancing health in daily life (health-related life skills, hereafter). In the present study, the life skills training effect on life style and adolescent health concerns were examined on school students.

The findings emerging from present study confirm that training life skills results in increasing Life Style and Health Concerns of Adolescents. Significant differences were observed between all the variables at .01 level of significance. In post condition, subjects have improved in overall life style, physical activity, sleep, nutrition \& health, mental/social health, injury \& violence, environmental quality, health care \& immunization. Significant difference was also obtained between pre and post condition on overall health concern, physical, social, psychosexual and moral health domain respectively. The overall adolescent health concern and in its domains are found to be increased significantly in post condition. The findings of the present research are in line with the findings of Aliloo (2004), Yadavari (2004), Yousefpoor (2009), Errecart and Ross (2002), Vertiainen (2004) which showed that training life skills results in increasing individuals' health condition. The findings are also supported by Cutinha (2012) and Srikala and Kishore (2010) who reported that education of the impact of model on life skill education of school children improves adjustment of the adolescents with teachers, school, increases prosocial behavior, coping with stress and self esteem as there was a significant difference between experimental and control groups. Present findings are also supported by a recent study conducted by Anand and Ritu (2015) in which they have observed that life skill training has a positive effect in youth problems and adjustment of adolescent girls going to school. 


\section{Effect of Life Skill Training on Life Style and Health Concern of Adolescents}

The results obtained from the present study showed that training life skills has been effective in improving life style and health concern of adolescent. Psychologists in recent decades have found that due to the increasing changes and complexities of society and expansion of social relations, preparedness of individuals especially the young generation to cope with difficult situations seems necessary. Life skill training is a program that its usefulness has been demonstrated in numerous studies. Generally, the findings of this study and similar studies indicate that through life skill training we can improve life style and the health concern of adolescents as prevention for health.

The findings reveal significant positive correlation between life style and health concern of adolescent which indicate that adolescents who have healthy life style enjoy good health and are more concerned about their health and vice-versa. The observed positive correlation support the view that healthy life style adolescents are able to think about their health with special reference to their physical, social, psychosexual and moral health. The present findings are supported by a recent Indian study conducted on adolescent school students by Ritu, Singh and Anand (2015) in which they found that students who have unhealthy life style such as excessive internet usage were less concerned about their health, while students who used internet within limit (healthy life style) were more concerned about their health. In other study, including several lifestyle factors, found a negative relationship between unhealthy lifestyle and mental and physical health (Pisinger et al., 2009).

The study is, however, not without limitations. Sample size is one of the major limitations of this study. The sample is consisted of private school students of urban locality only. The results of the study may not necessarily apply to all school students and possibly if investigated at larger school level the results would have been slightly different. All findings were derived from the self-reported questionnaires which may have some sort of bias, since participants may not be reliable in the report of their behaviours.

The study concludes that the intervention of life skill training is helpful for the school adolescents to take positive actions and improving their skills of life style and health concern. Life skills are the building blocks of one's behavior and need to be learnt well to lead a healthy, meaningful and productive life. Attempts should be made to understand the adolescent's problems and guide them in acquisition of life skills. The intervention on life skill development is a good support system for adolescents at the community level. Health promotion programs at educational institutions may be beneficial in raising student awareness of their present and future health in relation to their lifestyle behaviours. According to the results of study, it should be the top priority for authorities and health care managers to train school teachers for the healthy life style to the students and provide them facilities to choose healthy behaviors. Based on the results, health care providers should encourage adolescents to do more physical activities. Moreover, educational organizations should provide sport fields and develop sport facilities and 


\section{Effect of Life Skill Training on Life Style and Health Concern of Adolescents}

equipments in the schools and increase sport hours to encourage about the life style of young adolescents. It is also necessary to inform students and their families about healthy nutrition principles and application of different methods for nutritional education in order to modify and correct wrong nutritional habits. Schools could organize appropriate programs for teaching healthy life styles to the adolescents and as a result will enhance the community health.

Health promoting life style could provide a comprehensive and extensive spectrum of health for adolescents, educators and school psychologist could provide interventional programs for health concern and healthy life style based on the present condition for students. It is necessary to prioritize implementation of health related life skill programs in order to change and modify the unhealthy life style related factors.

\section{Acknowledgments}

The author appreciates all those who participated in the study and helped to facilitate the research process.

Conflict of Interests: The author declared no conflict of interests.

\section{REFERENCES}

Adams, M. H., Bowden, A. G., Humphery, D. S., Mc Adams, L. B. (2013). Social support and health promotion lifestyles of rural women. Online Journal of Rural Nursing and Health Care 2000.

Aliloo, M. (2004). The effect of training life skills on mental health of Iranian medical students at Oloum Pezeshki University.

Amir Khani, M., Motlagh, M., Sedaght, M., Namazy, R., Ardalan, G., Haghdost, A. (2008). Health status, risky health behaviors of students based on academic year 2006-2007. Isfahan: Isfahan University of Medical Sciences. Persian.

Anand, M. and Anju (2014). Adolescent Health Concern Inventory. Delhi: Prasad Psycho Corporation, ISO9001: 2008 certified org.

Anand, M., and Ritu (2015). Life skill training for youth problems and adjustment. Journal of the Indian Academy of Applied Psychology. Vol. 41, No. 2, 314-322.

Bagheri, N., and Bahrami, M., (2011). Life skills education on students' knowledge and attitudes towards drug use and self-esteem, Journal of Psychology and Education, Tehran University, Year VI, No. I, pp. 78-76

Baroogh, N. S., Nuktehdan, H., Kazemnejad, A., Nuruzi, E. (2003). Comparing the lifestyles of first and final term female BS nursing students. Journal of Faculty of Nursing \& Midwifery, 9 (1-2):55-62. Persian.

Cutinha, J., (2012). Impact of life skill education on academic performance of adolescents. Souvenir XXX Annu. Nation. Conference of ISPSW on Emerging Trends in Professional Social Work, 5-7, January, 2012, Department of Psychiatric Social Work, Bangalore. 


\section{Effect of Life Skill Training on Life Style and Health Concern of Adolescents}

Dodd, L. J., Al-Nakeeb, Y., Nevill, A., \& Forshaw, M. J. (2010). Lifestyle risk factors of students: a cluster analytical approach. Preventive medicine, 51(1), 73-77. http://dx.doi.org/10.1016/j.ypmed.2010.04.005

Errecart, M., \& Ross,J. (2002). School health Journal. 61(1) 19-42.

Fromme, K., Corbin, W. R., \& Kruse, M. I. (2008). Behavioral risks during the transition from high school to college. Dev Psychol, 44(5), 1497-1504. http://dx.doi.org/10.1037/a0012614

Gilbert, S. (2011). Assessing Emotional Intelligence Ungifted And Non-Gifted High School Student; Outcomes Depend On The Measure. Intelligence, 4, 369-391.

Greene, G. W., Schembre, S. M., White, A. A., Hoerr, S. L., Lohse, B., Shoff, S., Blissmer, B. (2011). Identifying clusters of college students at elevated health risk based on eating and exercise behaviors and psychosocial determinants of body weight. Journal of the American Dietetic Association, 111(3), 394-400.

Halperin, A. C., Smith, S. S., Heiligenstein, E., Brown, D., \& Fleming, M. F. (2010). Cigarette smoking and associated health risks among students at five universities. Nicotine \& tobacco research: official journal of the Society for Research on Nicotine and Tobacco, 12(2), 96-104. http://dx.doi.org/10.1093/ntr/ntp182

Li, G., Zhang, P., Wang, J., Gregg, E. W., Yang, W. and Gong, Q. (2008). The long-term effect of lifestyle interventions to prevent diabetes in the China Da Qing Diabetes Prevention Study: a 20-year follow-up study. The Lancet, 371: 9626: 1783-89.

Neumark Sztainer, D. (2006). Eating among teens: Do family mealtimes make a difference for adolescents' nutrition? New Directions for Child and Adolescent Development, 111: 91-105.

Norman, M. and Kaplan, M. D. (2004). Lifestyle modifications for prevention and treatment of hypertension. The Journal of Clinical Hypertension, 6(12):716-719.

Ochieng, B. M. (2006). Factors affecting choice of a healthy lifestyle: implications for nurses. British Journal of Community Nursing, 11(2):78-81.

Penter, M. (2012). The Effect Of A Metacognetive Intervention On Approach To And Self Regulation Of Learning In Baccalaureate Nursing Students. Journal Of Nursing Education, 44 (7), 297-304

Pisinger, C., Toft, U., Aadahl, M., Glumer, C. and Jorgensen, T. (2009). The relationship between lifestyle and self-reported health in a general population: the Inter99 study. Preventive Medicine 49:418-423

Rafifar, S., Ahmadzadasl, M., Esmaily, M., Dezhpasand, S., Parsinia, S., and Khosronjad, M. (2005). Health promotion. Tehran: Mehrravash. Persian.

Ritu, Karamvir Singh and Madhu Anand (2015). Internet Usage and Health Concern among Urban Adolescents. School Psychology: Enhancing Psychological Competencies by Panch Ramalingam and Indranee Phooron Borooah. Puducherry, Puducherry Co-op, Book Society Ltd. 


\section{Effect of Life Skill Training on Life Style and Health Concern of Adolescents}

Sira, N., \& Pawlak, R. (2010). Prevalence of overweight and obesity, and dieting attitudes among Caucasian and African American college students in Eastern North carolina: A cross-sectional survey. Nutrition research and practice, 4(1), 36-42. http://dx.doi.org/10.4162/nrp.2010.4.1.36

Spratt, J., Shucksmith, J., Philip, K., and Watson, C. (2006). Part of who we are as a school should include responsibility for well-being: links between the school environment, mental health and behavior. Pastoral Care in Education, 24: 14-21.

Srikala, B. and Kishore, K. V. (2012). Empowering adolescents with life skills education in schools- School mental health program: Does it work? Indian J. Psychiatry, 52 (4): 344-349.

Steptoe, A., Wardle, J., Cui, W., Bellisle, F., Zotti, A.M., Baranyai, R. and Sanderman, R. (2002). Trends in smoking, diet, physical exercise, and attitudes toward health in European University students from 13 countries, 1990-2000. Prev. Med., 35, 97-104.

Tashiro, J. (2002). Exploring health promoting lifestyle behaviors of Japanese college women: perceptions, practices, and issues. Health Care for Women International, 23(1):59-70

Ulla Diez, S. M., \& Perez-Fortis, A. (2010). Socio-demographic predictors of health behaviors in Mexican college students. Health promotion international, 25(1), 85-93. http://dx.doi.org/10.1093/heapro/dap047

Vartiainen, E . (2004). Health promotion .1(3), 269- 283

Vaughan, E. L., Corbin, W. R., \& Fromme, K. (2009). Academic and social motives and drinking behavior. Psychology of addictive behaviors: journal of the Society of Psychologists in Addictive Behaviors, 23(4), 564-576. http://dx.doi.org/10.1037/a0017331

Von Bothmer, M.I. and Fridlund, B. (2005). Gender differences in health habits and in motivation for a healthy lifestyle among Swedish University students. Nurs. Health Sci., 7, 107-118.

White, H. R., McMorris, B. J., Catalano, R. F., Fleming, C. B., Haggerty, K. P., \& Abbott, R. D. (2006). Increases in alcohol and marijuana use during the transition out of high school into emerging adulthood: The effects of leaving home, going to college, and high school protective factors. Journal of Studies on Alcohol, 67(6), 810-822.

World Health Organization, (1994). The development and dissemination of life skills education: An overview. Geneva: Division of Mental Health, World Health Organization.

Yadavari, M. (2004). The effect of training life skills on general health, Self-respect and selfexpressing of Iranian high school girls students. General psychology M.A thesis, Islamic Azad University-Ahvaz branch.

Yousefpoor, M. (2009). The effect of training life skills on mental health improvement of physically handicapped individuals in Tabriz rehabilitation center. General psychology M.A thesis, Islamic Azad University-Tabriz branch.

How to cite this article: Ritu (2017), Effect of Life Skill Training on Life Style and Health Concern of Adolescents, International Journal of Indian Psychology, Volume 4, Issue 2, No. 95, ISSN:2348-5396 (e), ISSN:2349-3429 (p), DIP:18.01.163/20170402, ISBN:978-1-365-84231-3 